This item was submitted to Loughborough's Research Repository by the author.

Items in Figshare are protected by copyright, with all rights reserved, unless otherwise indicated.

\title{
The effect of ultrasonic excitation on the electrical properties and microstructure of printed electronic conductive inks
}

\section{PLEASE CITE THE PUBLISHED VERSION}

http://dx.doi.org/10.1109/ISSE.2015.7247978

\section{PUBLISHER}

(C) IEEE

\section{VERSION}

AM (Accepted Manuscript)

\section{PUBLISHER STATEMENT}

This work is made available according to the conditions of the Creative Commons Attribution-NonCommercialNoDerivatives 4.0 International (CC BY-NC-ND 4.0) licence. Full details of this licence are available at: https://creativecommons.org/licenses/by-nc-nd/4.0/

\section{LICENCE}

CC BY-NC-ND 4.0

\section{REPOSITORY RECORD}

Bournias-Varotsis, Alkaios, Russell A. Harris, and Ross J. Friel. 2019. "The Effect of Ultrasonic Excitation on the Electrical Properties and Microstructure of Printed Electronic Conductive Inks". figshare. https://hdl.handle.net/2134/17617. 


\title{
The Effect of Ultrasonic Excitation on the Electrical Properties and Microstructure of Printed Electronic Conductive Inks
}

\author{
Alkaios Bournias-Varotsis ${ }^{1)}$, Russell A. Harris ${ }^{1)}$ and Ross J. Friel ${ }^{1)}$ \\ 1) Wolfson School of Mechanical and Manufacturing Engineering, \\ Loughborough University, Loughborough, UK, \\ a.bournias-varotsis@lboro.ac.uk
}

\begin{abstract}
Ultrasonic Additive Manufacturing (UAM) is an advanced manufacturing technique, which enables the embedding of electronic components and interconnections within solid aluminium structures, due to the low temperature encountered during material bonding. In this study, the effects of ultrasonic excitation, caused by the UAM process, on the electrical properties and the microstructure of thermally cured screen printed silver conductive inks were investigated. The electrical resistance and the dimensions of the samples were measured and compared before and after the ultrasonic excitation. The microstructure of excited and unexcited samples was examined using combined Focused Ion Beam and Scanning Electron Microscopy (FIB/SEM) and optical microscopy. The results showed an increase in the resistivity of the silver tracks after the ultrasonic excitation, which was correlated with a change in the microstructure: the size of the silver particles increased after the excitation, suggesting that inter-particle bonding has occurred. The study also highlighted issues with short circuiting between the conductive tracks and the aluminium substrate, which were attributed to the properties of the insulating layer and the inherent roughness of the UAM substrate. However, the reduction in conductivity and observed short circuiting were sufficiently small and rare, which leads to the conclusion that printed conductive tracks can function as interconnects in conjunction with UAM, for the fabrication of novel smart metal components.
\end{abstract}

\section{INTRODUCTION}

Ultrasonic Additive Manufacturing (UAM) is an advanced manufacturing technique, which utilizes ultrasonic oscillation and normal force, applied through a cylindrical textured rolling sonotrode, to weld aluminium foils layer-by-layer. Periodical Computer Numerical Controlled (CNC) machining is used to create the desired 3D components directly from Computer Aided Design (CAD) data. The bonding process is controlled via three main process parameters: The normal force $(\mathrm{N})$ applied to the sonotrode, the sonotrode's oscillation amplitude $(\mu \mathrm{m})$ at a given and constant frequency of $20 \mathrm{kHz}$, and the linear speed $(\mathrm{mm} / \mathrm{s})$ of the sonotrode.

The main advantage of UAM compared to other metal additive manufacturing technologies is that the bonding occurs in the solid state at relatively low temperatures. A high degree of material plastic flow is encountered during the welding process, as well as various surface and volume effects, such as stick-slip phenomena at the welding interface and acoustic softening on the volume of the material [1]. The temperature developed during UAM has been experimentally measured by placing a thermocouple between two layers of foil for relatively low levels of oscillation amplitude [2], and with an infrared camera for higher levels of amplitude [3]. Both studies reported temperatures considerably lower than the melting point of aluminium: under $100^{\circ} \mathrm{C}$ on the first case and less than $250^{\circ} \mathrm{C}$ on the later. This suggests that UAM could potentially be used for the embedding of thermally sensitive components, such as electronic components and printed interconnection, inside metal additively manufactured parts.

Researchers have worked towards this goal and the successful encasing of a pre-packed thermal sensor [4], as well as directly written interconnections and antennae [5] inside CNC machined pockets of the UAM manufactured parts have been reported. In a similar area, research has been carried out to investigate the direct embedding of electronic 
insulating materials, deposited via screen printing, between two foil layers [6].

Although the potential of embedding freeform fabricated electrical circuitries and components within dense metal parts through the UAM process presents many new interesting opportunities, with applications in technological sectors ranging from aerospace to electronic packaging, the effect of the ultrasonic excitation, caused by the ultrasonic oscillations, has not been studied in depth yet. For this purpose, samples were prepared by consecutively depositing an insulating layer and silver conductive tracks, using screen printing, on UAM fabricated substrates, and then were exposed to different levels of ultrasonic excitation, using the UAM technology, as illustrated in Figure 1.

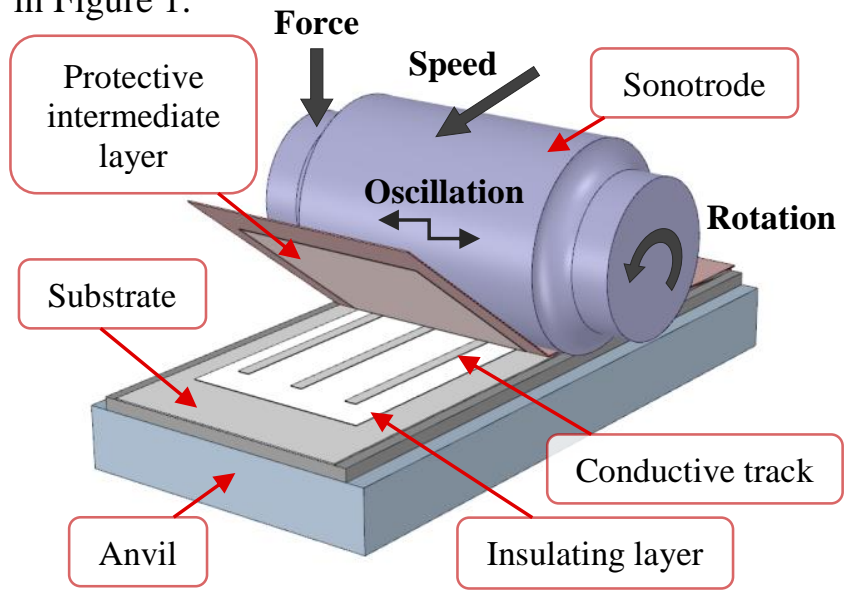

Figure 1 : Illustration of the experimental setup and sample.

\section{Materials AND Methodology}

In order to investigate in detail the effect of as many parameters as possible in the resistivity, the dimensions and the microstructure of a thermally cured screen printed silver conductive ink, a two level full factorial experiment was designed. The levels of the UAM process parameters used (i.e. the amplitude of oscillation, the normal force and the linear speed of the sonotrode) are detailed in table 1, and they were determined via preliminary experimentation. The low levels of amplitude and force were the lowest values, at which the UAM machine would opperate. Two different insulating materials were chosen: the XV501-T solder resist of SunChemicals and the LuxPrint $^{\mathrm{TM}} 8153$ dielectric ink of DuPont. These materials were picked for their wide use in the industry. Finally, in order to protect the conductive tracks from the roughness of the sonotrode, a $50 \mu \mathrm{m}$
Al 3003 H18 protective intermediate layer was placed over the conductive tracks as illustrated in Fig. 1. To simulate the encapsulation process of the conductive tracks between two insulating layers, a fifth parameter was chosen; the absence or presence of a $50 \mu \mathrm{m}$ polyester Mylar $^{\mathrm{TM}}$ film between the aluminium protective layer and the conductive tracks. The conductive silver polymer paste used was the C2080415P2 formulation of Gwent Electronic Materials.

Table 1 : UAM process parameters.

\begin{tabular}{ccc}
\hline \hline Parameter Name & Low Level & High Level \\
\hline Amplitude of Oscillation & $11 \mu \mathrm{m}$ & $16 \mu \mathrm{m}$ \\
\hline Normal Force & $500 \mathrm{~N}$ & $1000 \mathrm{~N}$ \\
\hline Linear Speed & $20 \mathrm{~mm} / \mathrm{s}$ & $40 \mathrm{~mm} / \mathrm{s}$ \\
\hline
\end{tabular}

For the preparation of the samples the following procedure was followed: Two $100 \mu \mathrm{m}$ thick Al 3003 H18 foils were welded using the previously experimentally determined optimum UAM process parameters (i.e. amplitude: $20 \mu \mathrm{m}$, force: $1400 \mathrm{~N}$, speed: $40 \mathrm{~mm} / \mathrm{s}$ ) on a $1.25 \mathrm{~mm}$ thick Al 1050 base plate, with the Solidica Alpha 2 UAM machine. Next, a layer of the insulating material was deposited on the aluminium surface, using a DEK 265 Horizon semiautomatic screen printer, and thermally cured in a convection oven according to the manufacture's recommendations (i.e. at $150{ }^{\circ} \mathrm{C}$ for $60 \mathrm{~min}$ for the XV501-T and at $130{ }^{\circ} \mathrm{C}$ for $10 \mathrm{~min}$ for the 8153). The process was repeated two times for the XV501-T and three times for the 8153 , to achieve the desired layer thickness of approx. $30 \mu \mathrm{m}$. Finally, three $50 \mathrm{~mm}$ long by $1 \mathrm{~mm}$ wide silver paste tracks were screen printed on the insulating layer and thermally cured at $130{ }^{\circ} \mathrm{C}$ for 15 min to create the samples illustrated in Figure 1. Those three tracks were later exposed simultaneously to the ultrasonic oscillation.

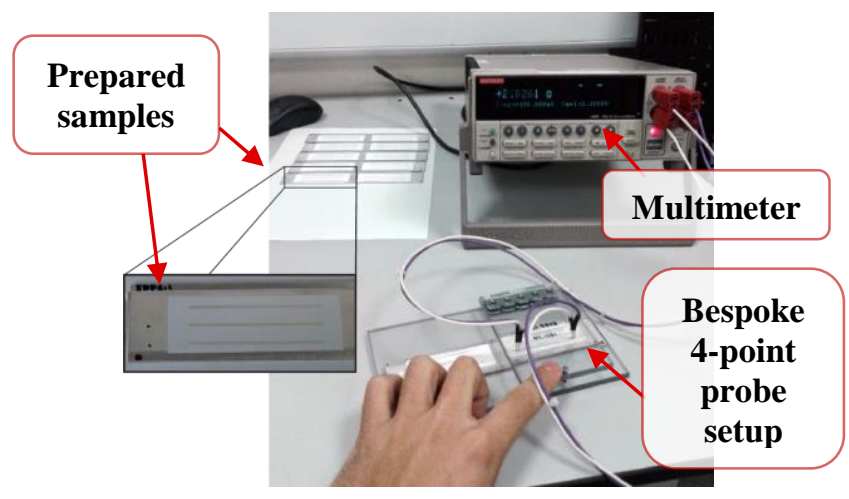

Figure 2 : Kelvin (4-point) probe measurement setup. 
Before the ultrasonic excitation, preliminary measurements according to ASTM F1896-10 [7] were carried out for the calculation of the resistivity of the conductive tracks. The resistance measurements were acquired using a bespoke Kelvin (4-point) probe setup and a Keithley 2425 benchtop multimeter (Figure 2) and repeated 3 times for each track. The dimensions (i.e. width and height) of the conductive tracks were measured by acquiring the profiles of four vertical sections with a TalySurf CLI 200 optical measurement system. The resulting measurements were averaged for each parameter and each treatment condition to calculate the average resistivity. After the ultrasonic excitation, the measurements described above were repeated to allow the calculation of the difference in the resistivity and dimensions, as in:

$\Delta \rho=\rho^{\text {after }}-\rho^{\text {before }}=\ldots$

$\ldots=1 / L \cdot\left(R_{\text {after }} \cdot W_{\text {after }} \cdot H_{\text {after }}-R_{\text {before }} \cdot W_{\text {before }} \cdot H_{\text {before }}\right)$

where $\rho(\mathrm{n} \Omega \mathrm{m})$ is the resistivity, $\mathrm{R}(\mathrm{m} \Omega), \mathrm{W}(\mathrm{mm})$ and $\mathrm{H}(\mu \mathrm{m})$ the measured resistance, width and height respectively and $L$ the distance between the measuring probes, which was kept constant during the measurements at $44.12 \mathrm{~mm}$.

A number of samples were cross-sectioned, mounted and polished. A Leica DM6000M optical microscope was used to measure the thickness of the insulating layer and to gain a greater insight into the process. In addition, a selection of samples was cross sectioned using a Focused Ion Beam and examined using Scanning Electron Microscopy (dual beam FIB/SEM). Their microstructure was compared to an unexcited control sample.

During this stage it was evident that issues with short circuiting between the conductive tracks and aluminium substrate were present, especially in the case of the 8153. Samples with resistance less than $0.5 \mathrm{M} \Omega$ between the tracks and the substrate were discarded and new samples were prepared and treated. Some of the treatments were duplicated to examine the repeatability of the process. In total, 37 samples ( $\mathrm{n}=19$ samples on the XV501-T and $\mathrm{n}=18$ samples on 8153) were included in the analysis.

\section{EXPERIMENTAL RESULTS}

An analysis of variance (ANOVA) was carried out for the interpretation of the experimental data. The outcomes of this analysis are summarized in Figure 3 and table 2 .

It was shown that an increase in the resistivity of the conductive tracks after ultrasonic excitation was evident and was dependent mainly on the material of the insulating layer. The resistivity of the tracks on the XV501-T increased by approx. $170 \%$, while on the 8153 by approx. $75 \%$. The large variability measured was attributed to randomness introduced by the UAM process and the conductive paste (e.g. the roughness of the sonotrode, uneven distribution of stresses and non-homogenous distribution of silver particles in the conductive tracks), and to the geometric inconsistencies of the screen printed tracks, especially in the case of the XV501-T.

Apart from the material of the insulating layer, the parameters that had a significant effect in the change in resistivity were the amplitude of oscillation and the presence of the protective polymer layer. The two levels of force and speed used in experimentation had a lesser effect on the response of the excited samples. There was a significant increase on the resistivity of the samples treated at high amplitude on the 8153 compared to those treated on low amplitude, but samples on XV501-T had the opposite response with less significant differences. The presence of the protective polymer layer actually introduced a larger increase in both the mean resistivity and variability of the response.

Due to the rolling effect introduced by the sonotrode, the dimensions of the conductive tracks changed: their average height was reduced, while their average width was increased, as shown in Table 2 . The variables with the greatest effect on this change were the normal force and the protective layer: high levels of force and the absence of the polymer layer caused greater deformation.

Table 2 : Mean value and std. deviation of resistivity, height and width of conductive tracks.

\begin{tabular}{rcc|cc}
\hline \hline & \multicolumn{2}{c|}{ XV501-T } & \multicolumn{2}{c}{$\mathbf{8 1 5 3}$} \\
\cline { 2 - 6 } & Before & After & Before & After \\
\hline \multirow{2}{*}{ Resistivity $[\mathrm{n} \Omega \mathrm{m}]$} & $368 \pm$ & $894 \pm$ & $150 \pm$ & $266 \pm$ \\
& 416 & 673 & 10 & 121 \\
\hline \multirow{2}{*}{ Height $[\mu \mathrm{m}]$} & $5.75 \pm$ & $4.14 \pm$ & $12.96 \pm$ & $9.18 \pm$ \\
& 1.40 & 0.64 & 1.30 & 1.78 \\
\hline \multirow{2}{*}{ Width $[\mathrm{mm}]$} & $1.25 \pm$ & $1.34 \pm$ & $0.88 \pm$ & $1.04 \pm$ \\
& 0.67 & 0.57 & 0.03 & 0.07 \\
\hline
\end{tabular}




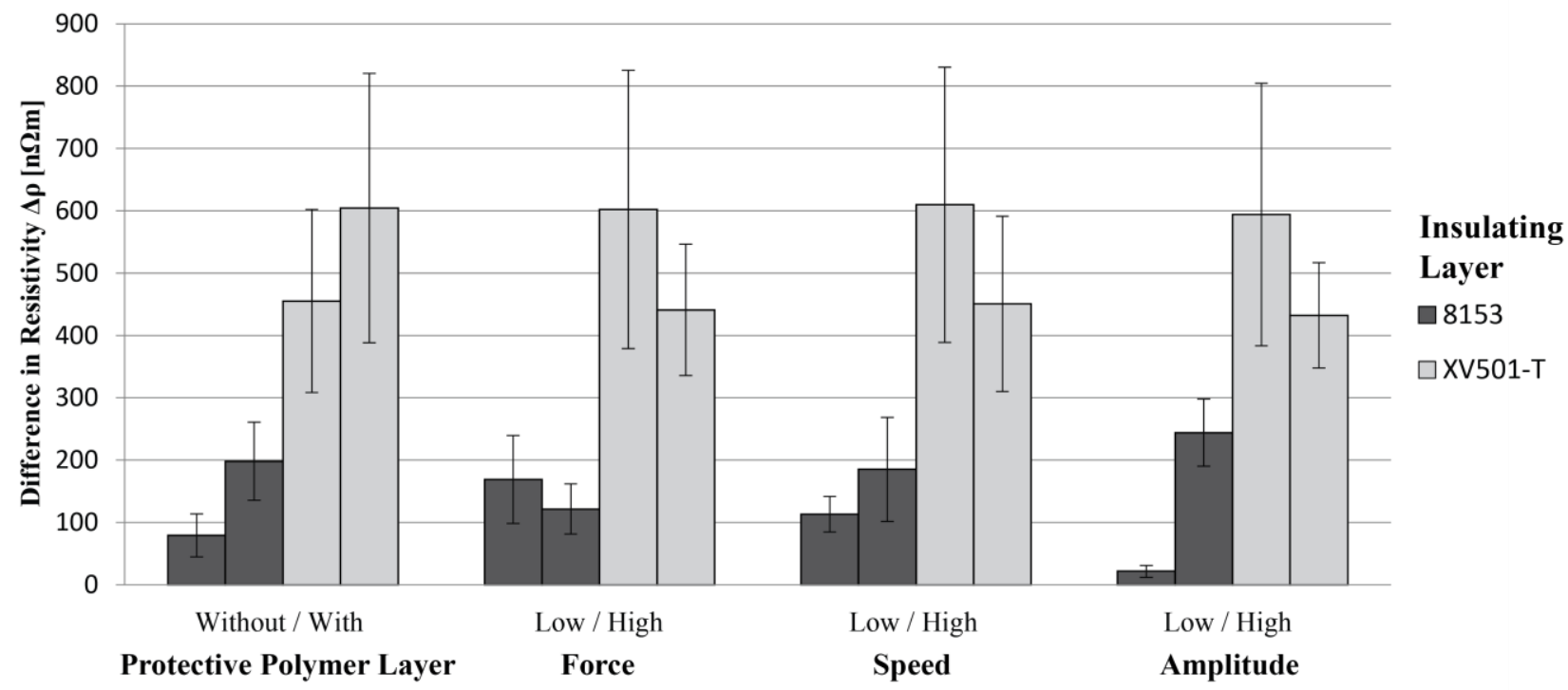

Figure 3 : Results summarising the result of the effect of each parameter on the difference in resistivity $\left(\Delta \rho=\rho^{a f t e r}-\rho^{\text {before }}\right)$. The mean values are presented. The error bars represent one standard error of the mean.

Two typical images obtained through optical microscopy from the cross-sectioned samples are presented in figure 4 for the XV501-T, and in figure 5 for the 8153. The mean thickness of the insulating layer, in the case of the XV501-T, was measured to be $31.4 \mu \mathrm{m}(\mathrm{s}=6.6 \mu \mathrm{m}, \mathrm{n}=6)$ for the control samples, and $29.4 \mu \mathrm{m}(\mathrm{s}=6.0 \mu \mathrm{m}, \mathrm{n}=30)$ for the treated sample. The mean thickness of the 8153 was measured to be $31.1 \mu \mathrm{m}(\mathrm{s}=5.0 \mu \mathrm{m}, \mathrm{n}=3)$ for the control samples and $26.9 \mu \mathrm{m}(\mathrm{s}=6.4 \mu \mathrm{m}, \mathrm{n}=25)$ for the treated samples. There was variation though on the layer thickness, with a minimum value of approx. 9 $\mu \mathrm{m}$ and a maximum of approx. $44 \mu \mathrm{m}$ for both insulating materials. A large variation in the thickness of the conductive layer was also evident, as illustrated in Figure 5.

In order to further investigate the reasons for the increase in resistivity, dual beam (FIB/SEM) was utilized to cross-section and image a small number of selected samples. In Figure 6, the three cross-sections of the silver tracks presented are printed on the XV501-T insulating layer, which showed greater increase in resistivity compared to the other material.

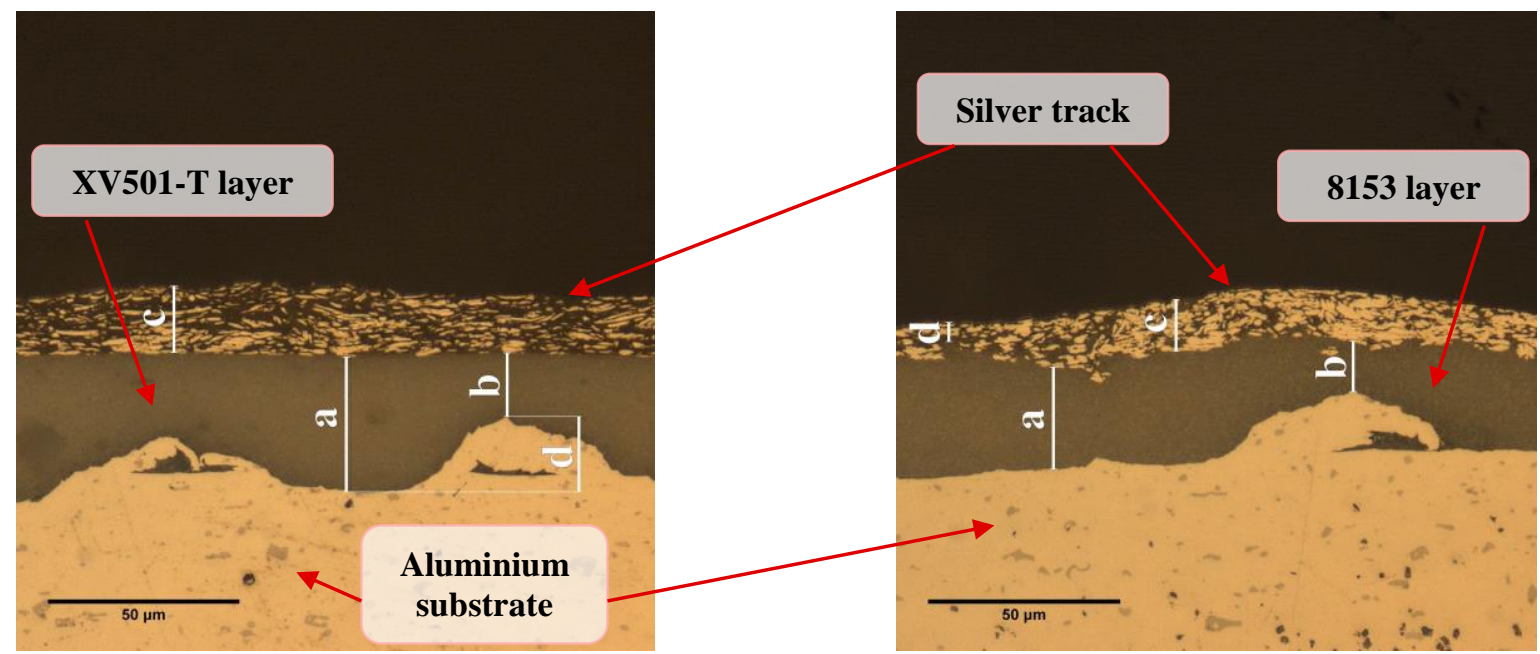

Figure 4 : Image from optical microscopy of sample on the XV501-T insulating layer $(\mathrm{a}=35.1 \mu \mathrm{m}, \mathrm{b}=16.5 \mu \mathrm{m}$, $\mathrm{c}=17.3 \mu \mathrm{m}, \mathrm{d}=18.6 \mu \mathrm{m})$.
Figure 5 : Image from optical microscopy of sample on the 8153 insulating layer $(\mathrm{a}=26.4 \mu \mathrm{m}, \mathrm{b}=13.1 \mu \mathrm{m}$, $\mathrm{c}=13.5 \mu \mathrm{m}, \mathrm{d}=5.3 \mu \mathrm{m})$. 

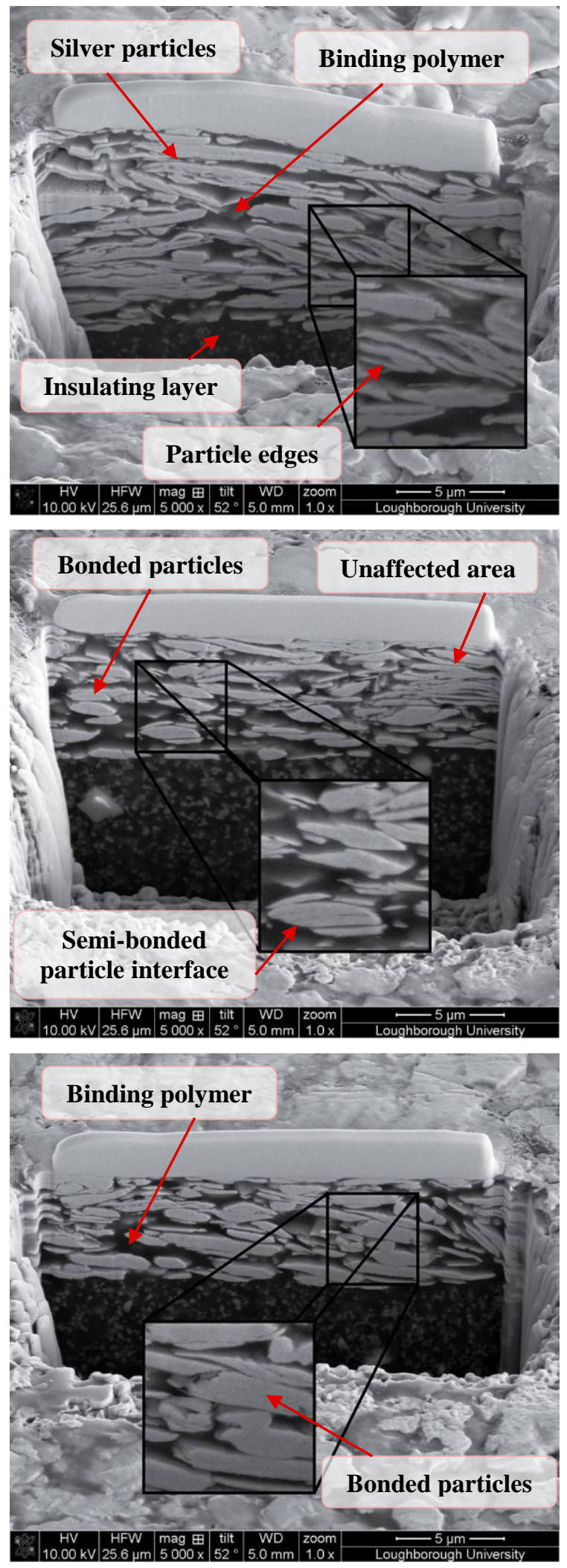

Figure 6 : Dual beam FIB/SEM images of silver tracks (top: control sample, middle: sample with lower resistivity, bottom: sample with higher resistivity).
Closer examination of the images revealed a change in the morphology of silver particles: after the excitation they appeared coarser. The thin whiskerlike particle edges, which are present in the untreated control sample, are greatly reduced in number in the excited samples. Evidence of particle bonding, similar to the metal bonding occurring in the aluminium foilfoil interface during UAM, were also found. Moreover, the apparent enlargement of the particle size caused an increase in the average size of the nonconductive space occupied by the polymer binder. All the effects described above are evident in the sample with the lower resistivity $(\rho=872 \mathrm{n} \Omega \mathrm{m})$, but more profound in the sample with the higher resistivity $(\rho=2279 \mathrm{n} \Omega \mathrm{m})$. Layer thickness measurements of the conductive layer were also taken to cross reference and verify the results of Table 1 .

\section{DiscuSSION}

The role of the insulating material in the process was crucial: both the print quality and the response to the ultrasonic excitation depended on the interaction between the conductive and insulating layers. The differences in the mean width of the conductive tracks suggested that the adhesion on the 8153 was stronger than that on XV501-T. This might have been connected with the lower initial resistivity and its increase after the treatment of the former. A previous study [6] found that XV501-T appeared to have relatively higher hardness compared to 8153 . This implied that their different mechanical properties (e.g. hardness, modulus of elasticity, dumping coefficient) affect the propagation of oscillations through the materials, which in turn has an effect in the change in resistivity.

Short circuits between the conductive tracks and the aluminium substrate in the case of 8153 were found. Optical microscopy showed that, even though the average thickness of the insulating layer was sufficient, the roughness of the substrate can result in locally thinner regions. Past research [8] measured the surface roughness of aluminium substrates manufactured under the same conditions and the maximum pick height was found to be approx. $17.5 \mu \mathrm{m}$. This is in accordance with the measurements shown in figure 4 . The roughness of the substrate, the relatively soft 8153 , and the complex mechanical phenomena occurring during UAM played a role in the development of the short circuits. This issue was 
not encountered on the XV501-T though, which suggests that it can be avoided.

Dual beam FIB/SEM imaging revealed that the silver particles of the conductive tracks were bonded after the exposure to ultrasonic excitation. The resistivity of the tracks was correlated with this phenomenon: a higher number of bonded particles corresponded to higher resistivity. This was attributed to an increase in the average non-conductive inter-particle distances.

\section{CONCLUSIONS AND FUTURE WORK}

In this study it was shown that the use of conductive screen printed tracks as interconnects inside UAM parts is possible. Ultrasonic excitation has a negative effect in the resistivity of the tracks and exposure to ultrasonic oscillations causes the conductive particles of the ink to bond. Nevertheless, the silver tracks remained conductive without an excessive increase in resistivity after the excitation.

The material of the insulating layer had the greatest effect on the final resistivity of the tracks. This was attributed to the different material and adhesive properties of the two insulating pastes examined. Further research will be carried out for the identification of alternative suitable insulating materials. Such materials should provide both a good surface for the printing of the conductive inks and should overcome the roughness of the aluminium substrate.

Future work will also focus on the identification of alternative dispensing systems for the conductive tracks, as well as the effect of the ultrasonic oscillation in different conductive materials, such as printed electronic copper and carbon conductive inks and different formulations of silver conductive inks.

\section{ACKNOWLEDGEMENT}

This work was supported by the Engineering and Physical Science Research Council (EPSRC) as part of the Centre for Innovative Manufacturing in Additive Manufacturing.

\section{REFERENCES}

[1] C. Y. Kong, R. C. Soar, and P. M. Dickens, "A model for weld strength in ultrasonically consolidated components," Proc. Inst. Mech. Eng. Part C J. Mech. Eng. Sci., vol. 219, no. 1, pp. 83-91, Jan. 2005.

[2] Y. Yang, G. D. Janaki Ram, and B. E. Stucker, "Bond formation and fiber embedment during ultrasonic consolidation," J. Mater. Process. Technol., vol. 209, no. 10, pp. 4915-4924, Jun. 2009.

[3] G. S. Kelly, M. S. Just, S. G. Advani, and J. W. Gillespie, "Energy and bond strength development during ultrasonic consolidation," J. Mater. Process. Technol., vol. 214, no. 8, pp. 1665-1672, Aug. 2014.

[4] E. J. Siggard, A. S. Madhusoodananb, B. Stucker, and B. Eames, "Structurally Embedded Electrical Systems Using Ultrasonic Consolidation (UC)," in Proceedings of the 17th Annual Solid Freeform Fabrication Symposium, 2006, pp. 70-83.

[5] C. C. J. Robinson, B. Stucker, A. J. Lopes, R. Wicker, and A. J. Palmer, "Integration of direct-write (DW) and ultrasonic consolidation (UC) technologies to create advanced structures with embedded electrical circuitry," 17th Solid Free. Fabr. Symp., pp. 60-69, 2006.

[6] J. Li, T. Monaghan, A. Bournias-Varotsis, S. Masurtschak, R. J. Friel, and R. A. Harris, "Exploring the Mechanical Performance and Material Structures of Integrated Electrical Circuits within Solid State Metal Additive Manufacturing Matrices," in Proceedings of the 17th Annual Solid Freeform Fabrication Symposium, 2014, pp. 857-864.

[7] ASTM, "ASTM Standard F1896-10 Test Method for Determining the Electrical Resistivity of a Printed Conductive Material.” ASTM International, West Conshohocken, PA, 2010.

[8] T. Monaghan, A. J. Capel, S. D. Christie, R. A. Harris, and R. J. Friel, "Solid-State Additive Manufacturing for Metallized Optical Fiber Integration," Compos. Part A. 